\title{
Use of polycarbonate plastic products and human health
}

\author{
R. K. Srivastava*, Sushila Godara
}

Department of Pharmacology, Pt. B.D. Sharma Post Graduate Institute of Medical Sciences and Pt. B.D. Sharma University of Health Sciences, Rohtak, Haryana, India

Received: 22 October 2012 Accepted: 11 December 2012

\section{*Correspondence to:}

Dr. R.K. Srivastava

Email:

rajnikant0629@yahoo.co.in

\begin{abstract}
As plastic and plastic products are being used in day to day at the cost of environment pollution, the human and wild life health and has become a global concern. Researchers found link between abnormal liver enzymes in the people and Bisphenol-A (BPA). Changes in insulin resistance, reproduction system, cardiovascular and brain function are also reported. BPA is used in the production of epoxy resins, polycarbonate resins, and polyester resins. BPA can leach out of certain plastic products including variety of modern goods, reusable food storage containers, eyeglass lenses, white dental fillings, sealants, medical equipments etc. In the body, BPA behaves as an estrogen receptor agonist and mimics estrogen hormone. Bisphenol-A (BPA) is a widespread endocrine-disrupting chemical (EDC) used as the base compound in the manufacture of polycarbonate plastics. Children and unborn and new born babies are at high risk of unwanted effects of BPA. Children suffer from chronic exposure to bisphenol A with manifestation of gastrointestinal problems, adrenal stress, immune dysfunction, toxic over load and neurological disorders. Some study in Japan has observed that more BPA can leach from polycarbonate products that have been scratched or is more than 4 years old or used bottles that have been subjected to bottle brushing or dishwashing and sterilization. People exposed to higher levels of BPA due to use of plastic food and beverages containers are more likely to develop cardiovascular diseases, diabetes and metabolic disorder. Recent studies have suggested that BPA exposure may have a role in the development of weight gain, insulin resistance, pancreatic endocrine dysfunction, thyroid hormone disruption, and several other mechanisms involved in the development of diabetes. Urinary BPA levels are found to be associated with diabetes mellitus independent of traditional diabetes risk factors. There is a concern of exposure of BPA to pregnant women that can affect the development of offspring in the womb. It is considered that women may be placing their fetuses at the risk by having dental sealants applied during pregnancy. Public should be educated about the use of plastic and plastic products which can prove to be hazardous and risk factor to many health problems of human and wild life.
\end{abstract}

Keywords: Bisphenol A, Polycarbonates, Plastics, Hormone disruptors, Diabetes

\section{INTRODUCTION}

With about 2 million tons used worldwide each year, $\mathrm{BPA}$ is one of the highest volume synthetic chemicals in the world. Traces of it leach from containers of polycarbonate which is hard, clear plastic and the epoxy linings of canned foods and beverages. For the 1455 US adults tested, the more BPA in their urine the higher their rates of heart disease and diabetes according to JAMA report. ${ }^{1}$ Researchers found link between abnormal liver enzymes in the people and BPA, suggesting that the chemical alters liver function. Changes in insulin resistance, reproductive system and brain function are reported. As the plastic and plastic products are being extensively used in day to day at the cost of environment pollution, the human and wild life health it has become a global concerns.

Bisphenol A (BPA) is 2, 2-bis (4-hydroxyphenyl) propane and is synthesized from acetone and phenol and is used in the production of epoxy resins, polycarbonate resins, and polyester resins. About $65 \%$ of the BPA 
produced is used to make polycarbonate and approximately $25 \%$ is used in epoxy resin production. The remaining $10 \%$ is used in other products such as tetrabromobisphenol. $^{2}$ Bisphenol A exists at room temperature as a white solid and has a mild "phenolic" or typical hospital odor. Polycarbonates are used for a variety of plastic products for consumer use. BPA is used in the manufacture of a great variety of products including compact discs, food cans lining, baby feeding bottles, thermal fax paper, car dash boards, safety helmets, bullet resistant laminates, adhesives, plastic windows, protective coating powder paints, polycarbonates bottles and the sheathing of electrical and electronic parts. BPA is also used in PVC production and processing where it may be used as a reactive inhibitor and as an anti-oxidant. ${ }^{3}$ BPA can leach out of certain plastic products including wide variety of modern goods, reusable food storage containers like water, milk and fruit juice; eyeglass lenses, white dental fillings, sealants, and medical equipments. Plastic bottles meant for storage of mineral water may also be a potential source of BPA. ${ }^{4}$ At high concentrations BPA was found to be estrogenic in MCF7 human breast cancer cells (E-screen assay), with the potency of the proliferative effect to be about 10-4 to 10-6 times that of $17 \beta$-estradiol. ${ }^{5,6}$ Estrogenic effects have also been characterized in rodents. BPA does not appear to bind to the oestrogen receptor but it does have a small oestrogen-type effect on cell proliferation in -vitro studies. $^{7}$ Recent studies report uterine and testicular effects among rats and mice exposed to BPA and prostate effect among mice having fetal exposure to BPA. ${ }^{6,8-12}$ In contrast, other recent experiments indicate few or no effects on reproductive function among rats administered BPA in the diet, although the BPA was relatively low. ${ }^{13,14}$ Traces amounts of BPA are known to be eluted from polycarbonate plastic wares and from resins used for food packaging. ${ }^{15}$ Recent studies have shown that BPA can leach out of certain products including the plastic lining of cans of food and drink packages e.g. water bottles, infant drinking bottles, compact discs, tableware, impact resistant safety equipments, white dental filling and sealants and many medical devices. In the body, BPA behaves as an estrogen receptor agonist and mimics estrogen hormone. In high doses this chemical causes negative health effects. Recently, it is observed that consumption of BPA by human leads to occurrence of breast cancer, fertility problems, miscarriages, precancerous prostate lesions, insulin resistance and behavioral changes. ${ }^{16,17}$

Children and particularly unborn and new born babies are at high risk of untoward effects of BPA. Children suffer from chronic exposure to bisphenol $A$ and with manifestation of gastrointestinal diseases, adrenal stress, immune dysfunction, toxic overload and neurological disorders. Legal limits are not set for low minimum levels which do not affect human health. It is found that heating polycarbonate laboratory flaps at $121^{\circ} \mathrm{C}\left(250^{\circ} \mathrm{F}\right)$ for 25 minutes released $2-5 \mu \mathrm{g} / \mathrm{kg}$ of BPA into water filled flasks. Some study in Japan has suggested that more BPA can leach from polycarbonate that has been scratched or is more than 4years old. It is found that scratched bottles from Philippines leached approximately $30 \mu \mathrm{g} / \mathrm{kg}$ of BPA and those from Korea leached over $15 \mu \mathrm{g} / \mathrm{kg}$ which are more than 5times the amount leached by new bottle. ${ }^{18}$ BPA is released from used bottles which have been subjected to bottle brushing or dish washing and sterilization. There are seven Plastic Codes given below which should be displayed on every plastic product by plastic manufacturers:

1. PET or PETE - questionable- depending on quality, repeated use cause the leaching of DEHA, a known human carcinogen. Light gauge containers which are meant for one time use only may cause these problems whereas; heavier gauge containers show no evidence of leaching chemicals.

\section{HDPE- OK- not known to leach unwanted chemicals.}

3. PVC or V-bad - strong evidence to show the leaching of DEHA, a known human carcinogen.

4. LDPE -OK- not known to leach unwanted chemicals although not as widely recycled as 1 or 2 .

5. PP-OK- not known to leach unwanted chemicals although not as widely recycled as 1 or 2 .

6. PS- Bad - suspected to possibly leach harmful carcinogens.

7. Assorted but include polycarbonate, nylon and acrylic and typical product applications are babies bottles and some water bottles - Bad - may contain leaching BP.

Pragmatically it is said that plastic codes $1,2,4 \& 5$ are generally considered "safer" plastics and 3,6 and 7 "bad" plastics because bad plastics have the risk of BPA exposure. It should be mandatory for the manufacturers to label plastic codes in the triangle recycling labels or imprints on plastic containers. The level of BPA leaching from old polycarbonate table wares used by children increased to $1.8-7.9(\mu \mathrm{g} / \mathrm{kg})$ as compared to $1-1.9 \mathrm{ppb}$ $(\mu \mathrm{g} / \mathrm{kg})$ for new table ware. Bile and co-workers investigated leaching from five gallon water carboys. ${ }^{19}$ The amount of BPA in water from five gallon carboys was found to range from ND (not detectable) to $5 \mu \mathrm{g} / \mathrm{l}$ in water stored for 39 weeks. ${ }^{20}$ Other scientists have found BPA and other contaminants in mineral water and wine stored in plastic bottles. ${ }^{15}$ People exposed to higher levels of BPA due to use of plastic food and beverages containers are more likely to develop cardiovascular diseases and diabetes.

\section{HUMAN EXPOSURE FROM FOOD CANS}

Human exposure can arise from a number of sources. The primary source of exposure is through the diet, while air dust and water are other possible sources of exposure. 
BPA in food and beverages accounts for majority of daily human exposure. Other exposure routes include BPA leading from baby's feeding bottles, water bottle and bleaching from dental fillings and sealants. BPA related substances present in drinking water via the materials used in the water supply system. Polycarbonate and polysulphones are used to produce bottles for storage of mineral water and so bottled water is also a potential source of BPA. Wine stored in plastic bottles may also be contaminated to same extent. BPA detection was found in the liquid portion of several types of vegetables (peas, artichokes, green beans, mixed vegetables, corns and mushrooms) taken from cans with epoxy resin linings. ${ }^{15}$ The association of plastics manufacturers in Europe (APME) has calculated that the maximum intake of BPA from food cans is approximately $0.8 \mu \mathrm{g} / \mathrm{kg} / \mathrm{day} .{ }^{16}$ Industry workers have also evaluated BPA migration from food cans and found the range from non detectable in beverages (less than $5 \mu \mathrm{g} / \mathrm{kg}$ to up $94 \mu \mathrm{g} / \mathrm{kg}$ in canned food with an average of $37 \mu \mathrm{g} / \mathrm{kg}$. ${ }^{17}$ The levels of BPA leading into different types of canned food are in different amount. Koji Arizono and co-workers reported to have found $127 \mathrm{ppb}(\mu \mathrm{g} / \mathrm{kg})$ of BPA in canned coffee. ${ }^{16}$ Also in one of the ten cans of alcohol, they sampled, BPA was detected at $13 \mu \mathrm{g} / \mathrm{l} .{ }^{21}$ Low levels of BPA have also been found to cause biological effects, and its mode of action appears to mimic that of the female hormone, estrogen. There is growing international concern about manmade endocrine disrupting chemicals (EDCs), because they can de-rail the development of offspring exposed in the womb. It is feared that they may be partly responsible for the decline in sperm counts and the increased rates of hormone related cancers, such as cancers of the breast, testes and prostate. Children and in particularly unborn and new born babies are at high risk. BPA has been found in placental cord blood at the levels of $0.4-1.6 \mathrm{ug} / \mathrm{kg}$ wet tissues, which means that the unborn child is being exposed to this substance. ${ }^{22}$ Accumulation of BPA in maternal blood serum may represent a risk to the fetus.

One study, for example have shown that although most BPA may be initially cleared rapidly, some of the parent compounds may remain in the blood and with repeated exposure; circulating concentration of BPA increases. This study in mice also suggests substantial individual variations in the BPA levels with around $10 \%$ of the animals showing approximately 10 fold higher BPA levels than their treatment group averages. ${ }^{23}$

It is found that heating polycarbonate laboratory flaps at $121^{\circ} \mathrm{C}\left(250^{\circ} \mathrm{F}\right)$ for 25 minutes releases $2-5 \mu \mathrm{g} / \mathrm{kg}$ of BPA in to water filled flasks. Some studies in Japan have suggested that more BPA can leach from polycarbonate that has been scratched or is more than four years old. It is found that scratched bottles from the Philippines leached approximately $30 \mu \mathrm{g} / \mathrm{kg}$ of BPA and those from Korea leached over $15 \mu \mathrm{g} / \mathrm{kg}$, more than 5 times the amount leached by new bottles. ${ }^{14}$
BPA is released from used baby's bottle which had been subjected to bottle brushing or dishwashing and sterilization. The amount leaching in to water (represent milk) and 3\% acetic acid (represent fruit juice) at elevated and lower temperature could be detected. The milk diluent (water) in used bottles was found to contain 10-20 $\mu \mathrm{g} / \mathrm{l}$ of BPA and one value even reloaded a level of $50 \mu \mathrm{g} / 1$. BPA was not detected in the liquid held in new polycarbonate bottles because levels were less than $10 \mu \mathrm{g} / 1$ which was the limit of detection. ${ }^{24}$ Knowing the fact that polycarbonate babies bottle causes harmful effects on health, so it is advisable to change the bottle at regular interval (perhaps 6 monthly) and also to change to a safer materials is preferable. BPA has also been found in tinned foods. It was found at levels in excess of $1 \mathrm{mg} / \mathrm{kg}$ of food in more than $10 \%$ of European samples. ${ }^{25}$ Fat containing food appears to be particularly affected, including mackerel, pork meat, anchovies and sardines.

Bisphenol $\mathrm{A}$ is one of a number of chemicals that can be blocking the actions of our natural hormones, particularly estrogen. Even at very low levels it has been linked reduced sperm production, increased prostate weight and endometriosis. It may also affect the onset of puberty in the offspring of some mammals.

\section{HUMAN EXPOSURE FROM DENTAL FILLINGS AND SEALANTS}

Human exposure to BPA and related estrogenic substances can also arise from certain composite dental fillings and sealants. Most composites and sealants used in dentistry are based on BPA diglycidyl ether Methacrylate (bis-GMA). The compounds leached included are bis-GMA, BADGE, BPA and bis-DMA which can be also a source of BPA. ${ }^{7}$ Although, bis-GMA was not estrogenic in test tube tests, it could be transformed in to active compounds in acid and alkaline media, as could BADGE. $^{7}$ Mariotti et $\mathrm{al}^{26,27}$ have subsequently identified that bis-GMA is estrogenic in animals. It is considered that women may be placing their fetuses at the risk by having dental sealants applied during pregnancy. ${ }^{28}$

The mechanisms by which bisphenol A is processed in the body have been very well characterized by a variety of studies on animals and in human volunteers. ${ }^{26}$ Recently published studies in which human urine samples were analyzed and indicate that exposure to bisphenol A is extremely low, in the range of 20-30 nanogram $/ \mathrm{kg} /$ day. ${ }^{29-31}$

\section{HUMAN EXPOSURE TO BADGE FROM FOOD CANS}

The greatest proportion of BADGE appeared in the oil surrounding canned fish. On the basis of food consumption data, it was calculated that human intake of BADGE from canned food would not exceed $3 \mu \mathrm{g} / \mathrm{kg} /$ day. The presence of chlorohydrins derivatives of BADGE 
raises particular concern because they have a similar structure as other genotoxic substances. ${ }^{32}$ It should be noted that both BPA and BADGE can form adducts on DNA. Some studies suggest that BPA behaves as a strong estrogen via nuclear $\mathrm{ERb}$ and indicate that findings obtained with BPA in mouse b-cells may be extrapolated to humans. ${ }^{33}$ This supports that BPA should be considered as a risk factor for metabolic disorders in humans.

\section{BISPHENOL A AS AN ENDOCRINE DISRUPTOR}

Bisphenol-A (BPA) is a widespread endocrine disruptor that produces insulin resistance and alterations in pancreatic b-cell function. ${ }^{34}$ It has been suggested that together with other endocrine disrupting chemicals (EDCs), BPA constitutes a risk factor for type 2 diabetes and other metabolic disorders. ${ }^{35-37}$ Recent work shows the association between increasing urinary BPA levels and diabetes mellitus. A $12.8 \%$ of diabetic patients show high BPA levels in urine samples $(4.20 \mathrm{ng} / \mathrm{ml}$ or $18 \mathrm{nM}){ }^{34}$ Moreover an association between urinary levels of BPA, obesity and insulin resistance in middle-aged and elderly Chinese adults has been recently described. ${ }^{37}$ The range of BPA levels found in humans is from 0.7 to $20 \mathrm{nM} .^{37,38}$ To support the evidence that BPA may be a risk for the development of diabetes it is critical to study its effect on human tissues involved in glucose and lipid metabolism, including the endocrine pancreas which is key in glucose homeostasis. The islet of Langerhans is the physiological unit of the endocrine pancreas; it is a group of 1500-3000 cells of five different types and the most abundant are bcells. ${ }^{39}$ The main function of b-cells is the biosynthesis and release of insulin in response to neurotransmitters, hormones and nutrients, the most important being glucose. The secretory response of b-cells depends on their electrical activity. This consists of oscillations of the membrane potential that range from electrically silent periods to depolarized plateaus on which $\mathrm{Ca}^{2+}$-action potential originate. ${ }^{40}$ Classically, stimulus-secretion coupling involves the closure of KATP channels after an increase in the ATP/ADP ratio because of the glucose metabolism. ${ }^{41}$ KATP channels are responsible for the resting membrane potential of b-cells and its closure elicits a depolarization that opens voltage dependent calcium channels and induces $\mathrm{Ca}^{2+}$ influx. ${ }^{42}$ As a consequence of the oscillatory membrane potential, a $\left[\mathrm{Ca}^{2+}\right] \mathrm{i}$ oscillatory pattern originates ${ }^{43-46}$, which triggers a pulsatile insulin secretion. In addition to the KATP dependent process of insulin secretion there is a KATP independent process which involves cAMP dependent phosphorylation. Beta cells express estrogen receptor a (ERa), estrogen receptor $b(E R b)$ and the G-protein coupled receptor (GPR30), also named GPER $1 .{ }^{47}$ The use of genetically modified mice has revealed the role of these estrogen receptors. ${ }^{48} \mathrm{ERa}$ is involved in the regulation of pancreatic insulin biosynthesis in response to both E2 and BPA. Remarkably, nanomolar concentrations of either BPA or E2 act via extra nuclear ERa to activate ERK1/2 and regulate insulin content. ${ }^{49}$
This action involves the activation of the transcription factor NeuroD1. In addition, activation of extranuclear $\mathrm{ERb}$ by physiological concentrations of E2 rapidly regulates $\mathrm{K}_{\mathrm{ATP}}$ channel activity, increases glucose stimulated $\left[\mathrm{Ca}^{2+}\right] \mathrm{i}$ signals and insulin release. It is important to clarify that action of $\mathrm{E} 2$ on $\mathrm{K}_{\mathrm{ATP}}$ channel activity was mimicked by specific agonist of ERb 2, 3-bis (4-hydroxyphenyl)-propionitrile (DPN) but not by the ERa specific agonist propylpyrazole-triol (PPT). Moreover KATP channel activity was not modified in ERa. These results indicated that ERb plays an important role in rapid regulation of insulin secretion in pancreatic b-cells. Bisphenol A imitated rapid estradiol regulation of $\mathrm{K}_{\text {ATP }}$ channel and calcium signaling ${ }^{50}$, however, whether $\mathrm{ERb}$ acting out of the nucleus is able to mediate BPA actions is still unknown.

The public should be made aware of hazards of BPA exposure to mankind by explaining them the observations of many researches. Health regulators should honestly show concern and uncertainties with regard to the amount of BPA exposure to the mankind. A pertinent area to explore the possibility of association of BPA with the incidences of diabetes type-2, breast cancer, prostate cancer, polycystic ovaries and thyroid dysfunctions should be well studied in rural and urban population of India.

Funding: No funding sources

Competing interests: There are no competing interests to declare

\section{REFERENCES}

1. Lang IA, Galloway TS, Scarlett A, Henley WE, Depledge $\mathrm{M}$, et al. Association of urinary bisphenol A concentration with medical disorders and laboratory abnormalities in adults. JAMA 2008;300:1303-10.

2. European Chemical News 1999. $18-24^{\text {th }}$ October: p22.

3. Staples C. Bisphenol A: An environmental assessment. Bisphenol A Task group, SPI, Washington 1996.

4. Fieldiing M, Fawell JK, Franklin GS. Exposure to endocrine disruptors via materials in contact with drinking water. Report No. DETR/DWI 4746, 1999. WRC plc, Marlow, Bucks.

5. Soto AM, Sonnenschein C, Chung KL, Fernandez MF, Olea N, Serrano FO. The E-SCREEN assay as a tool to identify estrogens: an update on estrogenic environment pollutants. Environ Health Perspect 1996;103 Suppl 7:113-22.

6. Welshons WV, Nagel SC, Thayer Ka, Judy BM, Vom Saal FS. Low dose bioactivity of xenoestrogens in animals: fetal exposure to low doses of methoxychlor and other xenoestrogens increases adult prostate size in mice. Toxicol Ind Health 1999; 15:12-25. 
7. Pulgar R,Olea-Serrano F, Novillo-Fertrell A, Pazos P, Pedrazer V, Navajos JM, Olea N. Determination of BPA related aromatic compounds released from bis-GMA based composites and Sealants by high performance liquid chromatography. Environ Health Perspect 2000;108:21-7.

8. Laws SC, Carey SA, Ferrell JM Bodman GJ, Cooper RL. Estrogen activity of octyphenol, nonylphenol, bisphinol A and methoxychlor in rats. Toxicol Sci 2000;54:154-67.

9. Papaconstantinou AD, Umbereit TH, Fisher BR, Goering PL, Lappas NT, Brown KM. Bisphenol Ainduced increase in uterine weight and alteration in uterine morphology in ovarectomized $\mathrm{B} 6 \mathrm{C} 3 \mathrm{~F} 1$ mice: role of the estrogen receptor. Toxicol Sci 2000;56:332-9.

10. Takahashi O, Qishi S.Testicular toxicity of dietary 2, 2-bis (4-hydroxyphenyl) propane (Bisphenol) in F344 rats. Arch Toxicol 2001;75:42-51.

11. Kubo K, Arai O, Ogata R, Omura M, Hori T, Aou S. Exposure to bisphinol A during the fetal and suckiling periods disrupts sexual differentiation of the locus coeruleus and of behavior in the rat. Neurosci Lett 2001;304:73-6.

12. Tohel A, Suda S, Taya K, Hashimoto T, Kogo H. Bisphenol A inhibits testicular functions and increases luteinizing hormone secretion in adult male rats. Exp Biol Med 2001;226:216-21.

13. Tyl RW, Myers CB, Marr MC, Chang TY, Seely JC, Brine DR, et al. Three generation reproductive toxicity study of bisphinol A administered in the diet to $\mathrm{CD}$ (Sprague-Dawley) rats. Toxicol Sci 2002;68:121-46.

14. Braybrook J. Pers. Comm. from Julian Braybrook of the laboratory of the Government Chemicals. E-mail dated $24^{\text {th }}$ January 2000.

15. Brotons J.A., Olea-Serrano MF, Villalobo M, Pedraza V, Olea N. Xenoestrogens released from lacquer coating in food cans. Environ Health Perspect 1995;103:608-12.

16. Howe SR, Borodinsky L, Lyon SR. Potential exposure to Bisphenol A from food contact use of epoxy coated cans. J Coatin Technol 1998;70:69-74.

17. APME- Epoxy Resins Committee. Bisphenol AOestrogenic activity, March 1997, Brussels.

18. Fast screening method for Bisphenol $\mathrm{A}$ in environmental water and in food by solid- phase microextraction (SPME). J Health Sci 1998;45:3946.

19. Biles JE, Mc Neal TP, Begley TH, Hollifield HC. Determination bisphinol A in reusable polycarbonate food contact plastics and migration to food stimulating liquids. J Agri Food Chem 1997;45:3541-4.

20. Larroque M, Vian L, Blaise A, Brun S. Methods de dosages des manomeres residuels des resins exposydiques dans des stimulants du vine. J Chromatogra 1998;445:107-17.

21. Takao Y, Chui Lee H, YASHU HIRO I, Kohra S, Tuminago N, Arizono K. Fast screening method for
Bisphenol $\mathrm{A}$ in environmental water and in food by solid-phase microextraction (SPME). J Health Sci 1999;45:39-41.

22. Kawamura Y, Sano H, Yamada T. Migration of bisphinol A from coatings to drinks. J Food Hygenic Soc Japan 1999;40:158-65.

23. Takada H, Isobe T, Nakada N, Nishiyama H, Iguchi $\mathrm{T}$, Irie $\mathrm{H}$, Meri C. Detection of Bisphenol A and nonylphenols in human umbilical cords. Abstract B6. Endocrine Disruptor $1^{\text {st }}$ Annual Meeting at Kyoto, Dec 11-12, 1998.

24. Tayor JA, Judy BM, Rottinghaus BA, Blackwell KJ, Rottinghaus GE, Alworth LC, Vom Saal FS, Welshons WV. Bisphenol A bioaccumulates in the serum of pregnant mice. Available at http://e.hormone.tulane.edu/pdfs_ehormone/posters1 999/Taylor.pdf. Accessed 20 October 2012.

25. Scientific Committee on food (SCF): Opinion on BPA diglycidyl ether (BADGE) expressed on $24^{\text {th }}$ March 1999. European Commission, Brussels. Available http://ec.europa.eu/food/fs/sc/scf/out28_en.html. Accessed 9 September 2012.

26. Mariotti A, Soderhalm KJ, Johnson S. The in vivo activity of bisGMA on murine uterine weight, nucleic acids and collagen. Eur $\mathbf{J}$ Oral Sci 1998;106:1022-7.

27. Mariotti A, Johnson S, Sodrehalm K-JM. The estrogenic effect of bis GMA on estrogen-sensitive target tissues. J Dent Assoc 1997;76:323-31.

28. Volkel W, Colnot T, Csanady GA, et al. Metabolism and kinetics of bisphenol $\mathrm{A}$ in humans at low doses following oral administration. Chem Res Toxicol 2002; 15:1281-7.

29. Arakawa C, Fujimaki K, Yoshinaga J, et al. Daily urinary excretion of bisphenol A. Environ Health Prev Med 2004;9:22-6.

30. Tsukioka T, Terasawa J, Sato S, et al. Development of analytical method for determining traces amounts of BPA in urine samples and estimation of exposure to BPA. J Environ Chem 2004;14:57-63.

31. Matsumoto A, Kunugita N, Kitagawa K, Isse $\mathrm{T}$, Oyama T, et al. Bisphenol A levels in human urine. Environ Health Perspect 2003;111:101-4.

32. Committee on Toxicity of Chemicals in Food, Consumer Products and the Environment. Statement on Bisphenol A Diglycidyl Ether (BADGE) in canned Foods, 1997. Available at http://cot.food.gov.uk/cotstatements/cotstatementsyrs /cotstatements 1997/402216. Accessed 2 July 2012.

33. Soriano S, Alonso-Magdalena P, Garci'a-Are'valo M, Novials A, Muhammed SJ, et al. Rapid insulinotropic Action of Low Doses of Bisphenol-A on Mouse and Human Islets of Langerhans: Role of Estrogen Receptor $\beta$. PLoS One 2012;7(2):e31109. doi:10.1371/journal.pone.0031109.

34. Nadal A, Alonso-Magdalena P, Soriano S, Quesada I, Ropero AB. The pancreatic beta-cell as a target of estrogens and xenoestrogens: Implications for blood 
glucose homeostasis and diabetes. Mol Cell Endocrinol 2009;304:63-8.

35. Alonso-Magdalena P, Quesada I, Nadal A. Endocrine disruptors in the etiology of type 2 diabetes mellitus. Nat Rev Endocrinol 2011;7:34653.

36. Hectors TL, Vanparys $\mathrm{C}$, van der Ven $\mathrm{K}$, and Martens GA, Jorens PG, et al. Environmental pollutants and type 2 diabetes: a review of mechanisms that can disrupt beta cell function. Diabetologia 2011;54:1273-90.

37. Neel BA, Sargis RM. The paradox of progress: environmental disruption of metabolism and the diabetes epidemic. Diabetes 2011;60:1838-48.

38. Shankar A, Teppala S. Relationship between Urinary Bisphenol A Levels and Diabetes Mellitus. J Clin Endocrinol Metab 2011;96:3822-6.

39. Wang T, Li M, Chen B, Xu M, Xu Y, et al. Urinary Bisphenol A (BPA) Concentration Associates with Obesity and Insulin Resistance. J Clin Endocrinol Metab 2012;97:E223-7. doi:10.1210/jc.2011-1989.

40. Vom Saal FS, Nagel SC, Timms BG, Welshons WV Implications for human health of the extensive bisphenol A literature showing adverse effects at low doses: a response to attempts to mislead the public. Toxicology 2005;212:244-52.

41. Vom Saal FS, Akingbemi BT, Belcher SM, Birnbaum LS, Crain DA, et al. Chapel Hill bisphenol A expert panel consensus statement: integration of mechanisms, effects in animals and potential to impact human health at current levels of exposure. Reprod Toxicol 2007;24:131-8.

42. Ben-Jonathan N, Hugo ER, Brandebourg TD. Effects of bisphenol A on adipokine release from human adipose tissue: Implications for the metabolic syndrome. Mol Cell Endocrinol 2009;304:49-54.

43. Hugo ER, Brandebourg TD, Woo JG, Loftus J, Alexander JW, et al. Bisphenol A at environmentally relevant doses inhibits adiponectin release from human adipose tissue explants and adipocytes. Environ Health Perspect 2008;116:1642-7.

44. Melzer D, Rice NE, Lewis C, Henley WE, Galloway TS. Association of urinary bisphenol a concentration with heart disease: evidence from NHANES 2003/06. PLoS One 2010;5:e8673. doi: 10.1371/journal.pone.0008673.

45. Alonso-Magdalena P, Morimoto S, Ripoll C, Fuentes E, Nadal A. The estrogenic effect of bisphenol A disrupts pancreatic beta-cell function in vivo and induces insulin resistance. Environ Health Perspect 2006;114:106-12.

46. Alonso-Magdalena P, Laribi O, Ropero AB, Fuentes $\mathrm{E}$, Ripoll C, et al. Low doses of bisphenol A and diethylstilbestrol impair $\mathrm{Ca} 2+$ signals in pancreatic alpha-cells through a nonclassical membrane estrogen receptor within intact islets of Langerhans. Environ Health Perspect 2005;113:969-77.

47. Thomas C, Gustafsson JA. The different roles of ER subtypes in cancer biology and therapy. Nat Rev Cancer 2011;11:597-608.

48. Alonso-Magdalena P, Vieira E, Soriano S, Menes L, Burks D, et al. Bisphenol A exposure during pregnancy disrupts glucose homeostasis in mothers and adult male offspring. Environ Health Perspect 2010;118:1243-50.

49. Wei J, Lin Y, Li Y, Ying C, Chen J, et al. Perinatal Exposure to Bisphenol $\mathrm{A}$ at Reference Dose Predisposes Offspring to Metabolic Syndrome in Adult Rats on a high-fat Diet. Endocrinology 2011;152:3049-61.

50. Bouskine A, Nebout M, Brucker-Davis F, Benahmed M, Fenichel P. Low doses of bisphenol A promote human seminoma cell proliferation by activating PKA and PKG via a membrane G-protein-coupled estrogen receptor. Environ Health Perspect 2009;117:1053-8.

doi: 10.5455/2319-2003.ijbcp20130103

Cite this article as: Srivastava RK, Godara S. Use of polycarbonate plastic products and human health. Int $\mathrm{J}$ Basic Clin Pharmacol 2013;2:12-7. 